\title{
Valores culturales, socioeconómicos, simbólicos e históricos y prospectiva tecnológica de la gardenia en Fortín de las Flores, Veracruz, México
}

Rodríguez Deméneghi, Marco Vinicio; Aguilar Rivera, Noé; Murguía González, J oaquín

Val ores culturales, socioeconómicos, si mbólicos e históricos y prospectiva tecnol ógica de la gardenia en Fortín de las Flores, Veracruz, México

CIENCIA ergo-sum, vol. 27, núm. 1, marzo-junio 2020|e70

Universidad Autónoma del Estado de México, México

Esta obra está bajo una Licencia Creative Commons Atribución-NoComercial-SinDerivar 4.0 Internacional.

Rodríguez Deméneghi, M. V., Aguilar Rivera, N. y Murguía González, J . (2020). Valores culturales, socioeconómicos, simból i cos e históricos y prospectiva tecnológica de la gardenia en Fortín de las Flores, Veracruz, México. CIE NCIA ergo-sum, 27(1). https://doi.org/10.30878/ces.v27n1a2 


\title{
Valores culturales, socioeconómicos, simbólicos e históricos y prospectiva tecnológica de la gardenia en Fortín de las Flores, Veracruz, México
}

Cultural, socioeconomic, symbolic and historical values and technological prospective of gardenia in Fortin de las Flores, Veracruz, Mexico

Marco Vinicio Rodriguez Deméneghi

Universidad Veracruzana, México

marcorodriguez05@uv.mx

Recepción: 11 de mayo de 2018

Aprobación: 23 de octubre de 2018

Noé Aguilar Rivera

Universidad Veracruzana, México

naguilar@uv.mx

Joaquin Murguia González

Universidad Veracruzana, México

jmurguia@uv.mx

\section{RESUMEN}

Se busca determinar vínculos culturales, históricos, sociales, religiosos y comerciales de la gardenia con la identidad de la región de Fortín de las Flores, la cual fue introducida como agronegocio en el siglo XIX, mediante un estudio descriptivo con enfoque metodológico cualitativo y de carácter interpretativo utilizando la técnica de estudio de caso, entrevistas y bola de nieve debido a la ausencia de publicaciones y datos confiables del cultivo. Los resultados estiman que diversos factores, primordialmente cambio de uso del suelo hacia plantaciones comerciales, cierre del ferrocarril de pasajeros con escala en Fortín y la creación de la autopista México-Veracruz, incidieron para que el viajero ya no se detuviera en esta región como turista y comprador de gardenias.

Palabras Clave: floricultura, valores, simbolismo, agroindustria.

\begin{abstract}
El goal of this paper is to determine cultural, historical, social, religious and commercial links of the gardenia with the identity of the region of Fortin de las Flores, Veracruz; introduced as agribusiness in the 19th century, through a descriptive study with qualitative methodological framework and interpretative approach, using the technique of case study, interviews and snowball, due to the absence of publications and reliable crop data. The results establish that by several factors, primarily changes in land use to other crops, the closure of the passenger railway station at Fortin and the creation of the Mexico-Veracruz highway and other impacted that the traveler no longer stop in this region as buyer tourist of gardenias.
\end{abstract}

KEYWORDS: Floriculture, values, symbolism, agroindustry.

\section{INTRODUCCIÓN}

En la Región de las Montañas, zona central del estado de Veracruz, se ubica el verde, floreciente y exuberante municipio de Fortín de las flores, en las coordenadas $18^{\circ} 54^{\prime}$ de latitud norte y $97^{\circ} 00^{\prime}$ de longitud oeste, a una altura de $1000 \mathrm{msnm}$. Limita al norte con los municipios de Chocamán y Tomatlán, al noreste con Ixhuatlán del Café, al este con Córdoba y al oeste con Naranjal, Ixtaczoquitlán, Atzacan y la Perla. Su distancia aproximada al 
sur de la capital del estado, Xalapa, por carretera es de $170 \mathrm{~km}$ (INAFED, 2010). Equivale aproximadamente a $0.10 \%$ del total del estado, con una superficie de $73.21 \mathrm{~km}^{2}$. La vegetación predominante es del tipo bosque de niebla o bosque mesófilo de montaña, donde destacan las plantas epifitas y trepadoras sobre los árboles. Asimismo, la agricultura ocupa el primer lugar de uso del suelo con $56 \mathrm{~km}^{2}$. El municipio cuenta con una población de 59761 habitantes, de la cual 34.9\% se encuentra en situación de pobreza y 5.6\% en pobreza extrema. Su suelo irregular se encuentra surcado por la barranca del Sumidero y la cima de Monte Blanco, que forman un contraste de bellos paisajes. La zona ha estado olvidada tanto por sus habitantes como por los investigadores en el desarrollo de proyectos que permitan a las nuevas generaciones visitar y conocer los orígenes de este lugar. Además, este municipio cuenta con una reserva ecológica de grande extensión conocida como El Corazón de Metlac (Vega, 2005). La infraestructura de servicios está conformada por seis hoteles, un centro de cabañas turísticas, veintiséis restaurantes, una compañía de transportes y seis agencias de viajes. Los principales recorridos agroturísticos son el del cultivo y procesamiento de café, plantaciones de café y velillo (hoja de plátano para tamales veracruzanos), cultivo de caña de azúcar y trapiches piloncilleros e invernaderos de flores.

El nombre de Fortín se le atribuye a que don Hernán Cortés (Cabral, 1966) ordenó a hispanos y criollos construyeran un "fortín" a mediados del siglo XVI, es decir, un tipo de pequeña fortaleza custodiado por un retén de soldados hispanos con el fin de vigilar y proteger el paso de las diligencias que transitaban por el antiguo camino del río Metlac (parte de la ruta entre la capital del virreinato al puerto de Veracruz), las cuales transportaban oro y pasajeros. En un sitio era frecuente encontrar asaltantes; por ello, a esta zona se le empezó a conocer como "El Fortín”. El pueblo de "El Fortín” inicialmente pertenecía al Municipio de Córdoba, pero en sesión solemne del 3 de agosto de 1930 obtiene el nombramiento de municipio, conformado por las congregaciones de Fortín, Monte Blanco, Zapoapita y Tlacotengo, que dejaron de pertenecer al municipio de Córdoba, y la congregación de Coapichapa a Ixtaczoquitlán, tal y como se puede apreciar en el Decreto 307 expedido por la Heroica Legislatura del Estado de Veracruz con fecha 4 de julio de 1930 y publicado en la Gaceta Oficial del Estado en el número 84. Este Decreto, en su artículo 2º señala que el municipio de nueva creación se denominará "Fortín" y su cabecera radicará en el pueblo de este nombre y al mismo tiempo deja asentado donde estarán ubicados los poderes. Con el paso de los años y con fecha del 27 de diciembre de 1954, según el Decreto número 114 expedido por la H. Legislatura del Estado y como se señala en su segundo apartado en donde enfatiza que la cabecera municipal se ha constituido como un centro de atracción que por sus características ha cobrado prestigio no sólo en la República sino dentro del turismo internacional, se eleva a dicho pueblo de Fortín a la categoría de Villa, con la denominación de "Fortín de las Flores", como resultado de la fama nacional e internacional que esta región había adquirido por el cultivo de ornamentales y de flores, de donde resalta la flor de gardenia que le dio una identidad única y especial a esta hermosa región, pero, tal y como lo señala Villalobos (1997), la denominación de "Fortín de las Flores" fue mucho antes que quedara asentada en un decreto, ya que se le atribuye a Álvaro Obregón, famoso militar y presidente de la República Mexicana (1920-1924), quien al viajar en el ferrocarril que comunicaba de la ciudades de Córdoba a la de México, con parada obligada en la estación de "El Fortín", los pobladores le ofrecieron ramos de olorosas y hermosas flores, con un exquisito aroma que se podía percibir desde los pasillos de descenso de la sencilla estación ferrocarrilera, pues en el periodo comprendido entre 1910 a 1920 la zona ya contaba con una prodigiosa producción y con un vasto número de otras especies florales en donde sobresalían la gardenia y la azucena, hecho que lo cautivó y expresara con admiración que esto era un "fortín" haciendo alusión a que había un fuerte, pero sobre todo era un fortín de las flores, de ahí que se le empezó a denominar a esta población como Fortín de las Flores. Posteriormente, en 1959 y con fecha del 12 de noviembre en nuevo Decreto, la Villa de Fortín de las Flores es elevada a la categoría de Ciudad, lo cual obedece a lo señalado en su artículo único (Ayuntamiento de Fortín, 2019): "En atención al progreso que en la actualidad ha alcanzado la Villa de Fortín de las Flores, Veracruz, en comercio, agricultura, densidad de población y obras de servicio público y social que en la misma existen se eleva la mencionada Villa, a la categoría política de Ciudad". 
No se puede hacer referencia al municipio de Fortín sin asociarlo con su producción y comercialización de flores, sus verdes paisajes y su clima benigno, que le han otorgado su fama como un lugar para el descanso, el disfrute y la relajación, tal y como se describe en la revista México Desconocido (2014: 88):

La pequeña ciudad fue fundada alrededor de la estación del tren llamada el Mexicano. Se conoce en la región como un pionero en el cultivo de flores desde el siglo XIX, y es mundialmente famoso como el exportador de flores número uno en México. Un viaje a Fortín es un regalo multicolor. En sus cien invernaderos encontrarás una gran variedad de flores, dominada por la más representativa, la gardenia. Pero así como se ha señalado en su historia, la flor gardenia ha sido adoptada como el símbolo de esta población.

Si bien en sus orígenes la vocación era agrícola enfocada a la producción de café, chayote, plátano y caña de azúcar (Martínez, 2015) y su biodiversidad aún muy apreciada (Landero-Torres et al. 2014, 2010; Fernández, 1986), Fortín ha reunido todas las características esenciales para representar y evocar la flor de gardenia integrando una tradición cultural que entrelaza el pasado con el presente, pero carente infraestructura turística durante muchos años (Vizcaíno, 1981).

Actualmente existe un incremento significativo de los cultivos dedicados a la horticultura ornamental tropical de forma familiar o como agroindustria (García-Alonso et al., 2014) debido a que las flores representan diversos valores y significados (Barbano et al., 2016).

Sin embargo, al no existir una base de datos y bibliografía reciente sobre las características del cultivo, número de productores y tipología, actores de la cadena de valor, entre otros, la información debe obtenerse mediante técnicas cualitativas (Blanco y Castro, 2007) y fuentes no convencionales de investigación científica como periódicos, revistas, notas de fecha y edición de varias décadas atrás.

En este sentido, la información fue registrándose mediante la técnica bola de nieve, como método de muestreo no probabilístico, de acuerdo con Montalvo et al. (2017). Es decir, una persona que conoce a un productor o comercializador de gardenias (informante clave) proporciona la referencia de otro y ese a su vez da los datos para contactar a otro más por comunicación verbal y entrevistas de diferentes productores que han heredado las huertas de sus padres y abuelos. Los actores comentan que nada más en el municipio de Fortín podrían haber existido hasta un poco más de 100 hectáreas exclusivamente de este cultivo.

\section{Gardenia (Gardenia Jasminoides Ellis)}

La gardenia tiene sus orígenes en el sur de China, Asia Oriental y de África tropical y subtropical. Ya en 1750 se conocían algunas de las especies muy apreciadas aún hoy en día, originarias de China (Rimache, 2009). Perteneciente a la familia Rubiaceae y al género Gardenia, la cual comprende una docena de especies, siendo Gardenia jasminoides Ellis la especie más común e importante, que ha dado lugar a numerosas y bellísimas variedades (Denny, 1948; Tiscornia, 1963; Davis, 1979; Del Cañizo, 1977). El contraste entre las numerosas flores blancas, intensamente fragantes y el contorno de las hojas de color verde brillante lo hace destacar como una de las plantas más bellas de exterior (Baines y Key, 1974).

La especie Gardenia jasminoides Ellis fue introducida en Gran Bretaña a mediados del siglo XVIII. Rápidamente se convirtió en una sensación hortícola debido a sus grandes flores blancas con aroma a jazmín. Al principio, la ubicación taxonómica de la especie fue desconocida por la falta de flores fértiles, pero se determinó que era muy diferente de un verdadero jazmín. El interés en esta planta a mediados del siglo XVIII no se limitaba a su uso ornamental, sino también se enfocó en el uso potencial de sus semillas como fuente de un tinte amarillo escarlata (Jarvis et al., 2014).

La taxonomía y variedades, condiciones agroecológicas, prácticas culturales para su producción son reportados por "The Plant List", [1] así como los sinónimos para Gardenia jasminoides Ellis. 
Históricamente, y por la información contenida en el archivo municipal de la ciudad de Fortín de las Flores, Veracruz, la gardenia fue introducida en esta región en 1882 por el señor Antonio Polanco gracias a un viaje que realizó a Europa y de donde trajo algunos ejemplares (Blanco, 2003). Se cuenta que en su momento algunos hacendados, como lo era este señor, fascinados por la fragancia y la hermosura de esta flor, reemplazaron huertas de café y en su lugar sembraron las gardenias; este hecho causó expectación entre los campesinos que hasta lo consideraron mentalmente enfermo, por lo que comenzaron a llamarlo "El viejo loco"(narrado así en la revista Voces Libres en 2005), pero ante todo pronóstico dicho cultivo empezó a fructificar favorablemente obteniendo un benéfico valor comercial. Quienes antes lo llamaron enfermo mental, después adoptaron dicho cultivo y muchas nuevas tierras de labor se convirtieron en jardín de gardenias o "gardeniales" (como se le empezó a nombrar a dichas huertas productoras). De este modo, la zona se vuelve un gran centro de producción a tal grado su importancia y fama que a la región se le empezó a denominar el "Fortín de las Flores", por la hermosa y perfumada flor blanca que desde esos momentos se convirtió en el símbolo de todo un pueblo floricultor, la cual con el pasar de los años se le dio un reconocimiento muy especial y perdurable plasmado dentro del escudo de armas del municipio (figura 1).

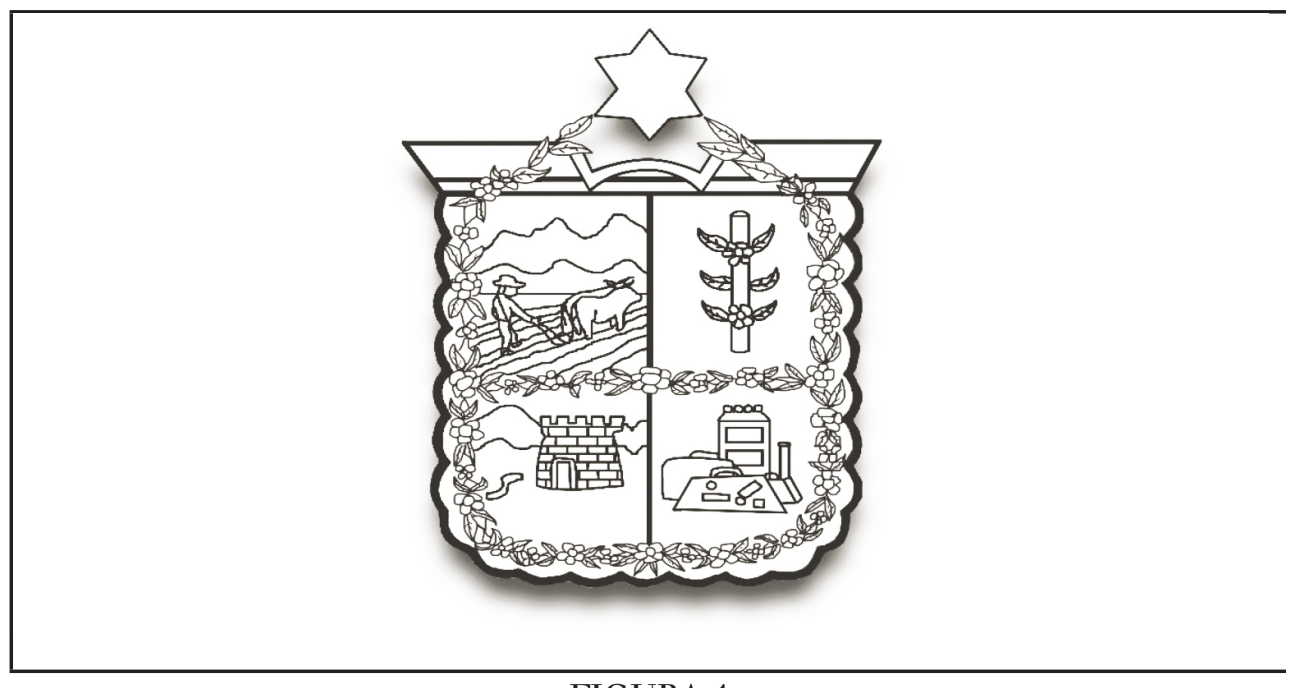

FIGURA 1

Escudo del municipio de Fortín, Veracruz, en donde se puede observar la cadena o collar con su flor representativa: la gardenia. Fuente: Ayuntamiento de Fortín (2019).

El escudo del municipio de Fortín, tal y cual se describe en la página oficial de dicho Ayuntamiento, está conformado de cuatro campos. El primero localizado en la parte superior izquierda representa la fuerza de su agricultura: un campesino guiando su yunta de bueyes para labrar la tierra simboliza lo que la población era o es (formada por campesinos). En el segundo campo, el lado superior derecho, simboliza la principal producción agrícola del municipio: caña de azúcar y café. El tercer campo ubicado en el lado inferior izquierdo está representado por una fortaleza que fue construida por los españoles, en donde permaneció un retén de soldados hispanos, al mando del capitán Villegas, que vigilaban y protegían el paso de las diligencias que transportaban oro y pasajeros de la capital del virreinato, al puerto de Veracruz. El cuarto campo se encuentra en el lado inferior derecho del escudo, donde aparecen unas maletas de viaje, con el trazo estructural de un hotel, que simboliza el turismo, circundando el escudo, y se puede apreciar una cadena o collar formado por la flor representativa de Fortín, "la gardenia". El escudo culmina en la parte superior, con una estrella o lucero, símbolo del buen clima de esta población y al imponente volcán Citlaltépetl o Pico de Orizaba, llamado también por los navegantes "Estrella de la Mañana”. 
En la plática abierta con los productores que actualmente existen en esta localidad, de acuerdo con el método de bola de nieve, comentan que por los relatos de sus abuelos y padres se conoce que en el pasado el cultivo de la gardenia inició como una actividad alterna al encontrar muy atractiva esta flor principalmente por su fragancia y color, así como por la rápida adaptación al clima de la región. Por su creciente mercado comenzó a cultivarse en mayor cantidad, aunado también a que la consideraban un cultivo noble, ya que, a diferencia del café, produce flores durante todo el año, convirtiéndolo en un apoyo seguro a su economía y por ello los productores lo adoptaron como su principal fuente de sustento. Así, la floricultura en los últimos años se ha identificado como una de las alternativas de diversificación de la producción agrícola en Veracruz (Landero-Torres et al., 2014; Hernández-Meneses et al., 2012; Murguía-González et al., 2016, 2003; De Latina et al., 2001).

\section{VALOR COMERCial, TURístico, SOCIAL y CULTURAL DE LA GARDENia}

La época dorada del cultivo de la gardenia en Fortín se puede considerar entre las décadas de 1940 y 1960 (Blanco, 2003), donde logró su mayor auge tanto como comercial, social y cultural. Fue cuando se contaba con el servicio de pasajeros que proporcionaba el ferrocarril el Mexicano en su importante ruta del Puerto de Veracruz hacia la Ciudad de México, el cual en la estación de Fortín tenía escala obligatoria y ahí se le vendía al viajante, además de comida, hermosos ramos de flores cultivadas en la región y principalmente de su flor representativa: la gardenia (figura 2). Estos pasajeros se convirtieron en el principal promotor publicitario para dar a conocer y gustar el aroma de esta perfumada flor a lo largo de la República Mexicana. También, este medio de transporte era utilizado para enviar a la Ciudad de México y a Guadalajara gran cantidad de canastones de flores para ser comercializados en sus principales mercados (Pasquel, 1966).

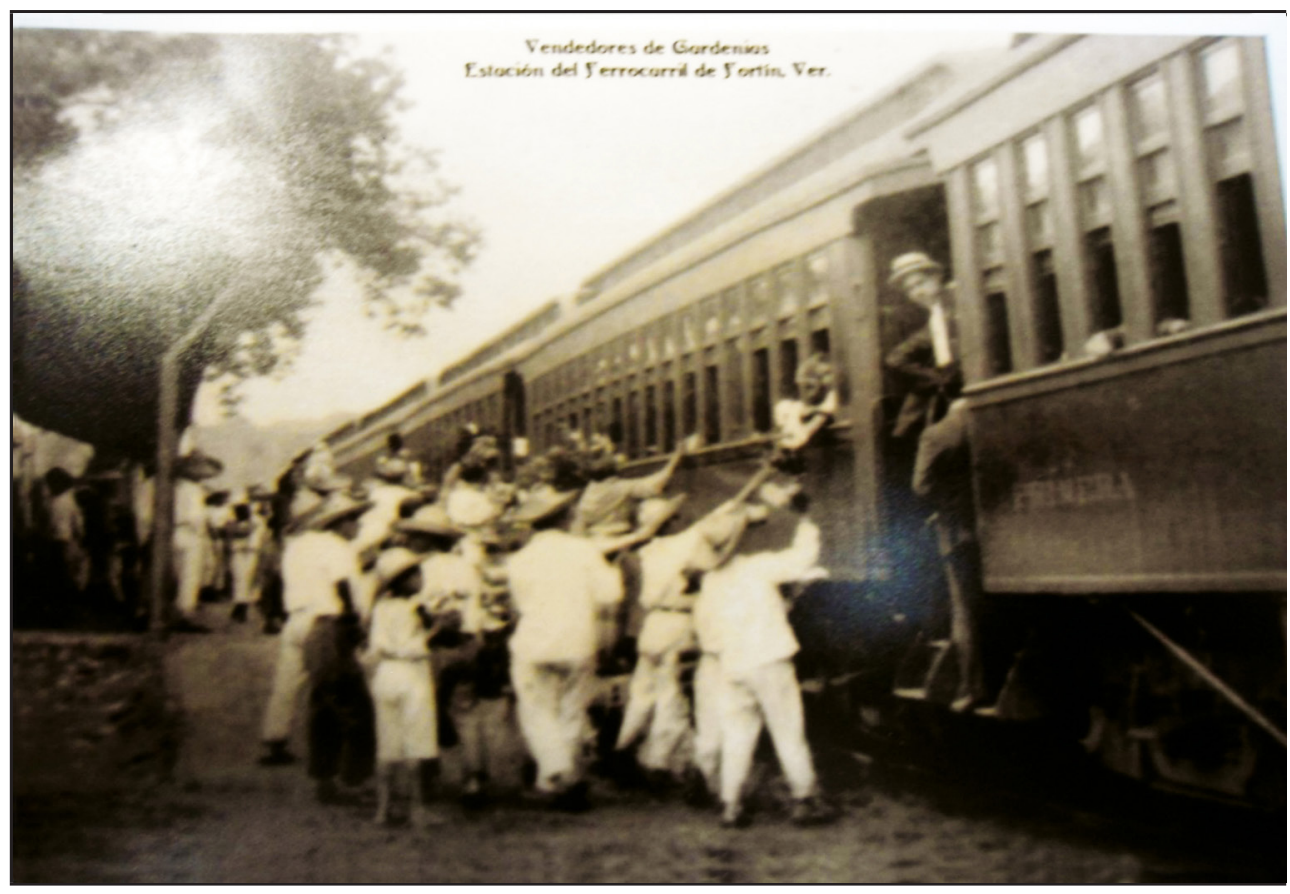

FIGURA 2

Vendedores de gardenia en la estación del ferrocarril en Fortín, Veracruz, en la década de 1940 Fuente: imagen proporcionada por el Departamento de Turismo del Ayuntamiento de Fortín (2017).

Se podría decir que el acontecimiento que logra elevar a la gardenia de Fortín al reconocimiento y fama internacional fue el hecho de que un reconocido, altruista y visionario hombre de negocios llamado don Antonio Ruiz Galindo, un planificador social (Romero, 1986) en la década de 1940, y dueño de un hermoso hotel que 
en su momento llevaba el nombre de Hotel Ruiz Galindo (actualmente Hotel Fortín de las Flores), empezó a esparcir en su alberca miles de botones florales de gardenia cultivadas en sus huertas, ya que además de empresario también contaba con grandes extensiones de tierra para el cultivo (Morales, 2010). Esta práctica, que ahora en nuestros días sería como el antecedente de un spa gigante, atrajo la atención de los miles de turistas tanto nacionales y extranjeros que arribaban a esta región. Esto sin olvidar que la ruta del tren el Mexicano entre la Ciudad de México y el Puerto de Veracruz hacía una escala en esta estación convirtiéndolo en un lugar privilegiado por la naturaleza, paz y tranquilidad que ahí se respiraba y esto atrajo a miles de visitantes que querían disfrutar de la hospitalidad de este pueblo, de su belleza natural y sobre todo tener la grata experiencia de nadar en la hermosa y perfumada piscina del Hotel Ruíz Galindo, la cual rebosaba de miles de frescos botones florales de la exquisita gardenia (figura 3).

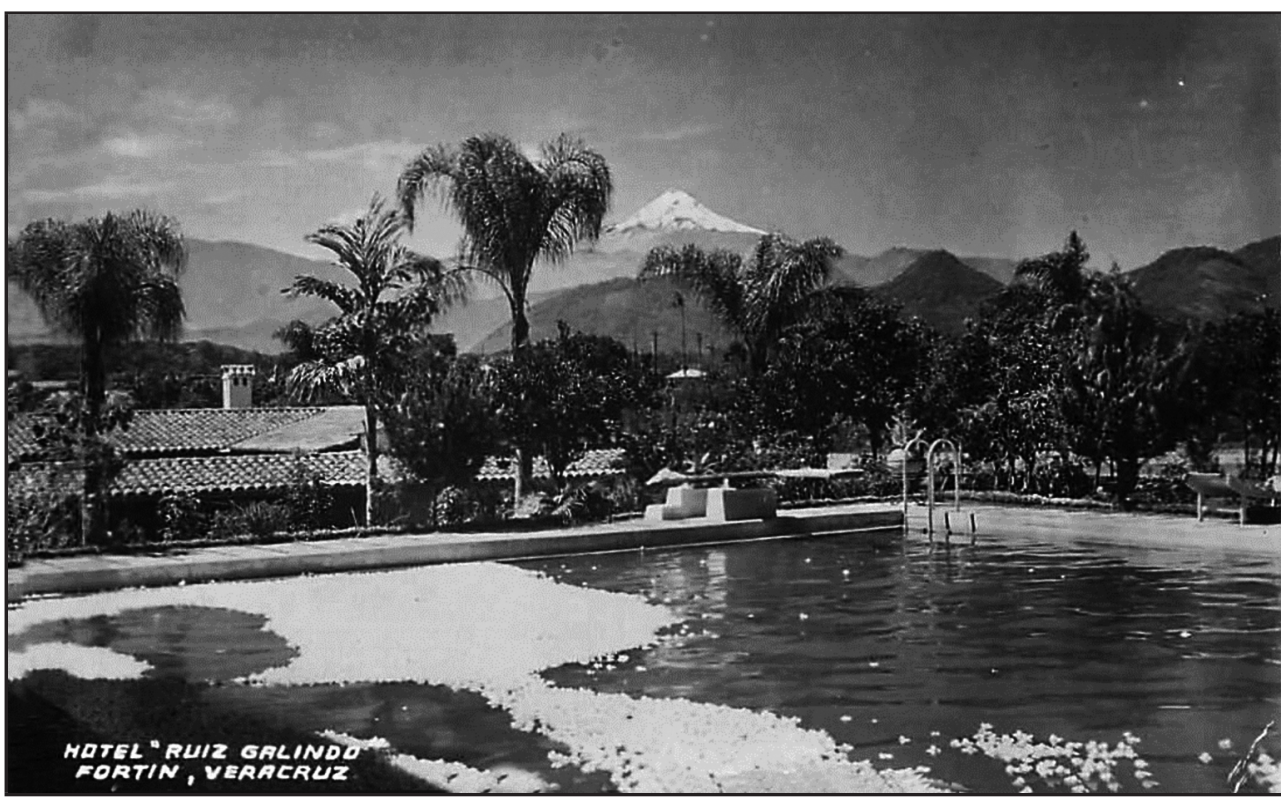

FIGURA 3

Postal de 1948. Se observa la piscina del Hotel Ruiz Galindo con las flores de gardenia Fuente: PicClik (2019).

Podemos incluir la acertada descripción de la ruta que realizaba el tren el Mexicano citada por el Diario del Istmo en cuya página web se puede encontrar una semblanza sobre el famoso Hotel Ruíz Galindo que se ubicaba en ese trayecto (Novo-Valencia, 2016):

La ruta terrestre México-Veracruz, conocida por entonces también como la Ruta Colonial, ofrecía dos hermosos recorridos a partir de San Hipólito Xochiltenango, Puebla, punto en donde se abría una bifurcación para poder escoger el camino que más le conviniera al viajero: uno, por la ciudad capital de Jalapa con una distancia de $452 \mathrm{~km}$, y, el otro, por la ciudad de Córdoba con una diferencia de 30 kilómetros menos de ventaja.

La segunda opción, que cuenta con su topografía y paisaje particulares, deparaba al turista el grandioso y emocionante acceso por las cumbres de Acultzingo, desde donde se inicia el espectacular descenso, del altiplano central al valle de Orizaba, para dar paso al vergel veracruzano lleno de cafetales, verdes platanares, plantíos variados de papaya, mango y otros deliciosos frutos de la comarca.

El parque de la hacienda Las Ánimas -en donde se ubica actualmente el Hotel Fortín de las Flores, antes Hotel Ruiz Galindo- constituía un gran atractivo por su colección de palmeras libanesas, balinesas, marroquíes y de 
otros tipos; la atractiva ruta que nos ocupa, sin perder nunca de vista al nevado Pico de Orizaba, hacía llegar a Fortín de las Flores, cuyo nombre ya daba idea de una ciudad-jardín plena de orquídeas, azaleas, nardos, azucenas y, sobre todo, olorosas gardenias.

Son innumerables las muestras de admiración por la belleza de este paradisiaco lugar, tal y como lo describe el historiador coscomatepecano don Jesús Domínguez Rosas en una obra de su autoría (1971) citado en la revista Consejo Ciudadano A. C. (2009: 11):

En el arte de la floricultura, ha hecho que el lugar tenga fama por sus camelias, rosas, orquídeas, tulipanes y bugambilias; sobre todo por la flor que es representativa del lugar: la gardenia. En México, en la capital, la blanca y aromosa gardenia, es un emblema de duelo por el uso que de ella se ha hecho en ofrendas, funerales[...]para nosotros[...] Siempre ha sido símbolo de boda y alegría[...] hoy, las pobres gardenias están condenadas a nadar con los cuerpos esculturales de las turistas norteamericanas en las frías albercas de Fortín de las Flores.

En nuestros días esas gardenias que han perfumado las aguas de las piscinas del famoso hotel continúan como un elemento primordial y significativo de la representatividad de una población y su imagen ha sido empleada para seguir atrayendo de la mano de este noble cultivo a todas esas personas que aman la naturaleza y la quietud de un pueblo con una historia unida. A lo largo del tiempo diferentes administraciones de los gobiernos municipales han incluido imágenes, señalética, señalización, publicidad, etc., De los cuales destaca la presencia de la gardenia representada en diversas formas y estilos, así como las diversas expresiones artísticas que pueden encontrarse en casas o bardas de habitantes de esta localidad que le otorgan un valor más allá de lo tangible de lo que dicha flor representa e identifica a un pueblo fortinense (figura 4).

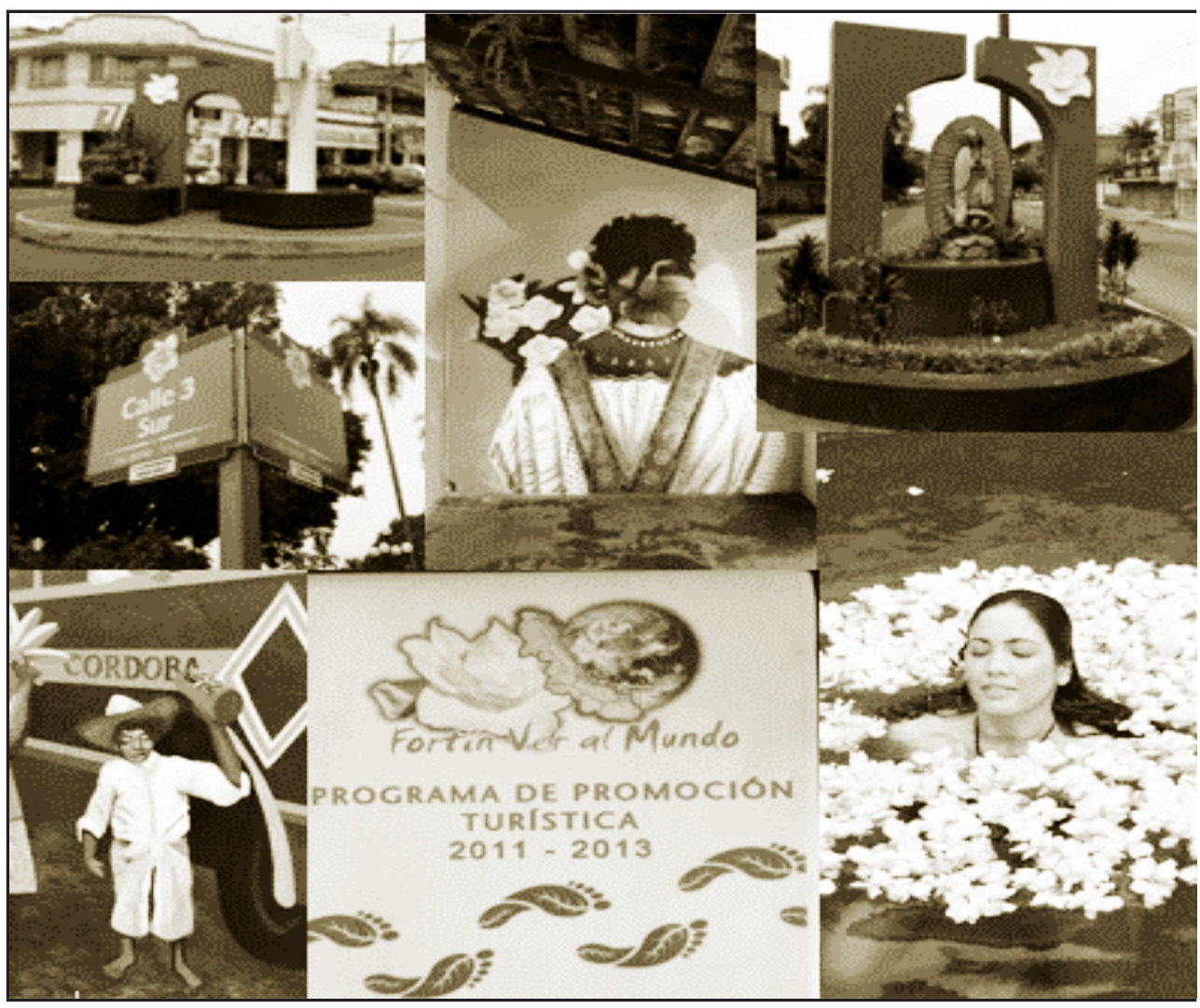

FIGURA 4

La gardenia como símbolo de identidad de una localidad expresada en diversas formas y estilos Fuente: imágenes proporcionadas por el archivo del Departamento de Turismo del Ayuntamiento Fortín 2017 y fotografias de Marco Rodríguez-Deméneghi. 
El municipio de Fortín con muy buenas razones para llevar como apellido "de las Flores" nos regala la belleza perfumada de sus gardenias (SEP, 1991), las cuales han sido el emblema de un pueblo a través del tiempo y de su historia. Osuna et al. (2016) y Escalante (2008) concluyeron que la floricultura representa una actividad de relevante significado económico, turístico y artístico que requiere ser valorada en su justa dimensión. Desde siempre, los seres humanos han valorado la expresividad y la belleza de las flores naturales. Las flores son elementos que dan un toque excepcional a la vida cotidiana. Además de representar una alternativa económica, la floricultura comprende otras implicaciones valorativas como la valoración artística, la valoración turística y cultural, la valoración afectiva y espiritual, la valoración ambiental y de la naturaleza, la valoración social, la valoración religiosa, la valoración histórica y cívica y la valoración económica.

La gardenia en Fortín desde su llegada en 1882 formó parte indiscutible de su historia en diferentes aspectos y ha sido fuente de inspiración para artistas; forma parte de la vida de familias campesinas y floricultoras, sustento para artesanos, alabanza a Dios, homenaje a héroes patrios y a benefactores sociales y en estos días fuente de ingresos para diversos productores de municipios aledaños al de Fortín que vieron en el cultivo de la gardenia una alternativa económica viable (Durán, 2006) y en donde a la fecha se ha observado un incremento en las zonas productoras con nuevos municipios participantes (Rodríguez-Deméneghi et al., 2016).

El desarrollo de la gardenia en Fortín comenzó como un cultivo generador de ingresos. El señor Polanco, floricultor reconocido, tuvo la acertada visión de que esta nueva especie de planta introducida en la región, y de la cual él ya había visualizado un agronegocio exitoso, podría proporcionar beneficios económicos sin imaginar la importancia y el valor cultural que esta flor adquiriría en esta región. La floricultura en México tiene gran importancia en el sector agrícola debido al alto valor de la enorme variedad de flores de corte, follaje, plantas y árboles que son comercializados a nivel nacional e internacional (Gómez-Gómez et al., 2014). El cultivo de la gardenia para flor de corte se constituyó en el municipio de Fortín como un cultivo exclusivamente regional novedoso y con un gran potencial económico. Sin embargo, no se dispone de estadísticas sobre la producción en la región, ya que la mayoría de las explotaciones son de tipo familiar o de traspatio y no se cuenta con un dato fidedigno de la superficie cultivada en su época dorada y en la actualidad, puesto que las estadísticas del sector oficial no la consideran (figura 5).

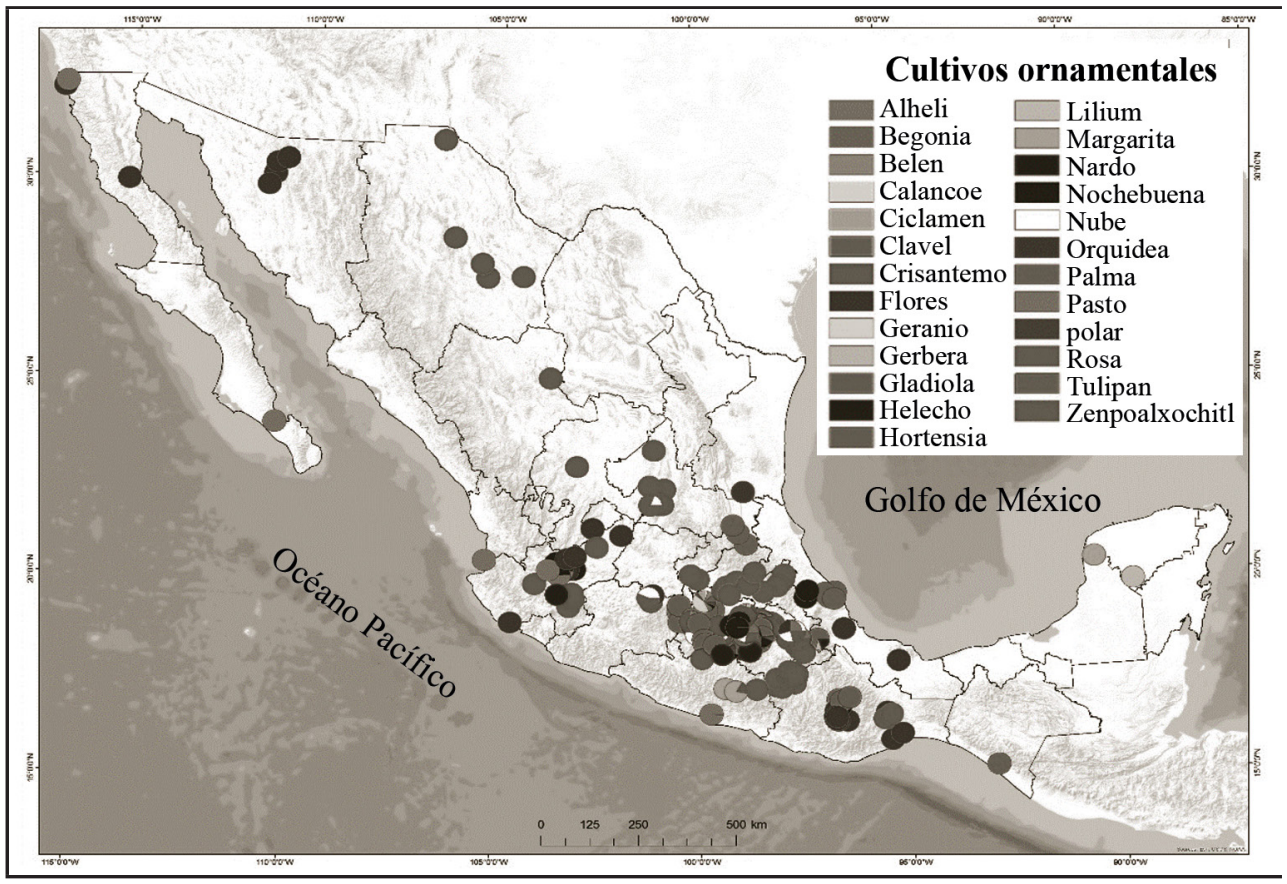

FIGURA 5

Producción de ornamentales en México Fuente: SIAP, 2017a; 2017b. 


\section{LA GARDENIA HOY}

En sus inicios, la producción de botones florales de estos gardeniales iba dirigido a satisfacer el mercado local y regional, pero también se enviaba diariamente de cuarenta a cincuenta canastones con miles de flores a grandes ciudades como la Ciudad de México y Guadalajara (Pasque, 1966), también se tiene la suposición de que estas flores traspasaron fronteras y fueron exportadas a los Estados Unidos, pero no hay una referencia confiable de ello.

Actualmente, aunque en menor escala, se sigue comercializando la gardenia en este municipio. Se venden por millares o cientos, y se colocan en cajas de cartón y se envuelven en hojas de plátano o de platanillo para conservar su frescura. Estados de la República Mexicana como Puebla, Tlaxcala la adquieren primordialmente para su empleo en los arreglos de iglesias para las diversas celebraciones de la fiestas patronales, muy comunes en nuestro país; de forma local, los comerciantes las adquieren y después las ofrecen en pequeños arreglos florales, que son muy del agrado de las personas para poner en pequeños altares de sus casas o negocios (González et al., 2007). Es importante señalar que en Fortín de las Flores se inició con la singular práctica de ofrecer la gardenia en "tubos" de tronco de plátano, tal como lo describe Cabral (1966: 30):

El Fortín hasta hace pocos años no pasaba de ser ciertamente una simple estación del ferrocarril el Mexicano donde los pasajeros de "subida" y de "bajada" compraban por unos cuantos centavos los típicos tubos de gardenia[...]

No se sabe quién o quiénes iniciaron con esta peculiar tradición que hasta ahora en nuestros días se sigue conservando, pero uno de los objetivos primordiales de poner las flores en un tubo de tronco de plátano, además de la protección que provee, es para aprovechar el agua que contiene en su interior, lo cual conserva fresca a las flores al mantenerse hidratadas y por consiguiente es más perdurable su vida de anaquel.

Dicha tradición es muy antigua como lo señala doña Leonor Morales de 72 años de edad y 60 años vendiendo tubos de gardenia. Dicha práctica le fue transmitida por una anciana que también llevaba muchos años dedicándose a la venta de estos tubos en la estación del tren, por lo que considera que dicha tradición puede tener más de 100 años. Ahora, como ella comenta, al no existir más el servicio de pasajeros del tren en Fortín, sale a vender sus tubos de gardenia en el parque principal o a un tianguis de ropa muy importante que cada miércoles se instala en la región. En el parque de floricultores el Paradero, ubicado a la entrada de la ciudad, se pueden observar hermosos tubos de gardenia ofrecidos para su venta por locatarios del mismo como es el caso del señor Sabino Florencio Quiterio, quien lleva también muchos años conservando dicha tradición (figura 6).

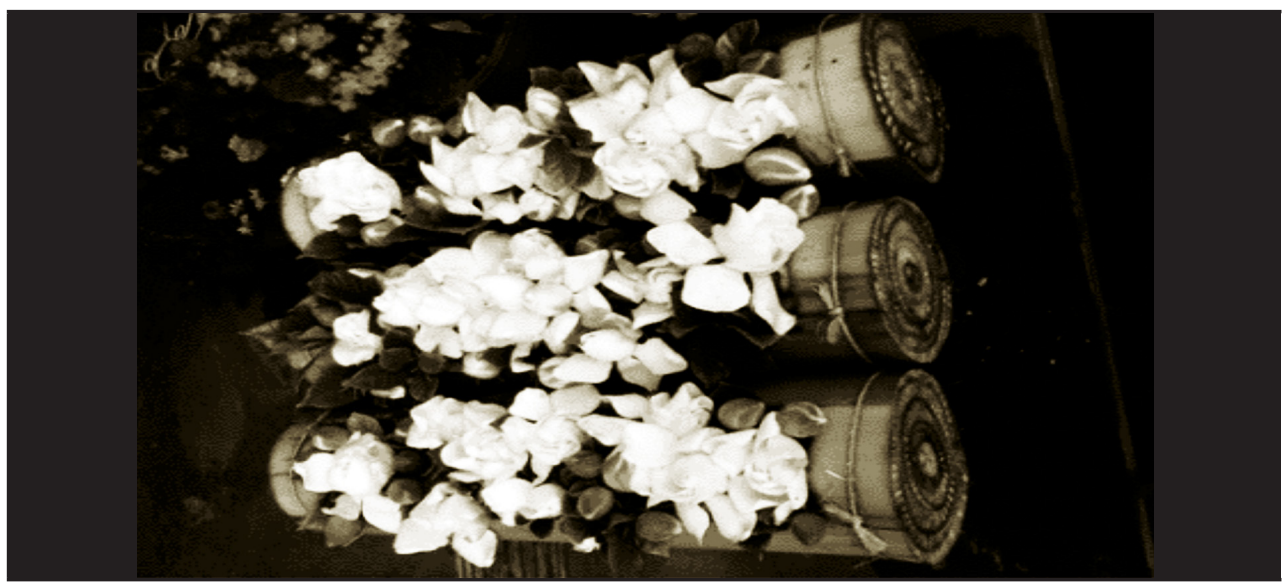

FIGURA 6

Producción y comercialización de la gardenia en Fortín de las Flores, en donde resaltan los tradicionales tubos de gardenia en tronco de plátano Fuente: fotografía tomada por Marco Rodríguez-Deméneghi. 
Podemos encontrar el valor que representa la gardenia plasmada en diversas acciones y situaciones: desde una corona de flores en su escudo hasta el recuerdo de una hermosa alberca perfumada y una estación de tren inundada de flores blancas en donde su comercialización era pieza importante dentro de la economía de un municipio, en las representaciones y ceremonias religiosas, así como en la visión poética de artistas y de la población en general que han visto y sentido la gardenia como parte importante de su identidad. Al respecto, la apreciada señora María del Carmen Sáinz Guevara (figura 7), de 90 años de edad, fue quien diseñó el traje típico de gala de la mujer fortinense. Comenta que este traje surgió a raíz de una convocatoria que en 1980 lanzó el Comité Pro-Cincuentenario de los festejos debido a que Fortín fue elevado a municipio, que en ese momento el doctor José Pedro Lazcano fungía como presidente, la cual buscaba poder expresar en un atuendo toda la hermosura y características tan especiales de esta región central de las altas montañas. Para la creación de este traje, ella confiesa que no realizó ningún tipo de investigación, sino que su inspiración se basó en experiencias, vivencias y sentimientos propias; comentó también que incluir la gardenia en el traje de la mujer fortinense se debe a que esta flor es la representativa de Fortín, ya que en la década de 1940 se podría decir que esta localidad era un enorme jardín cultivado por esta especie, por lo que es un emblema del lugar. Villalobos (1997) también señala que la diseñadora de este hermoso traje al confeccionarlo consideró que cuando se fundó Fortín no existía en él un grupo étnico, sino grupos de familias y hombres de buena voluntad.

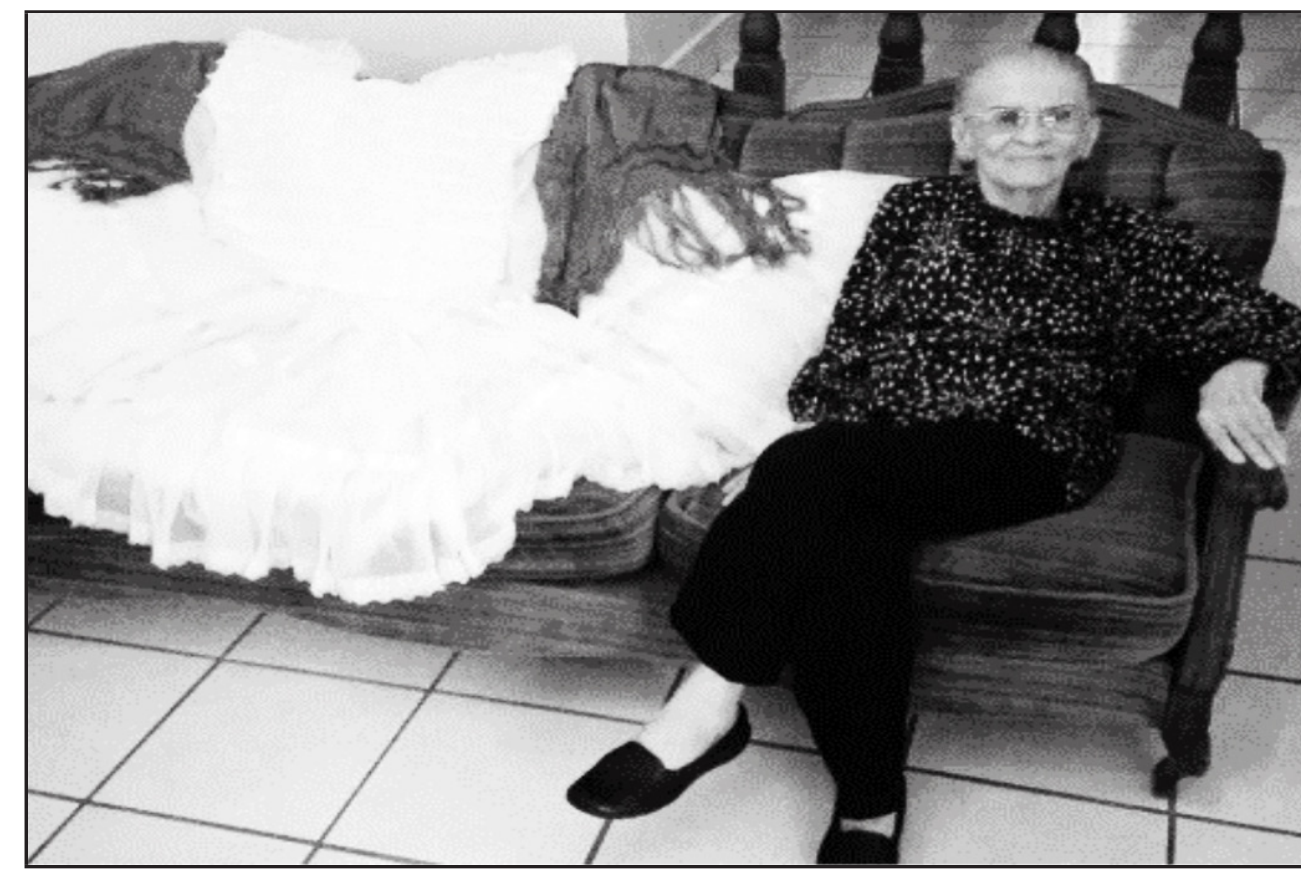

FIGURA 7

Doña María del Carmen Sáinz Guevara, creadora del traje típico de gala de la mujer fortinense Fuente: fotografía tomada por Marco Rodríguez-Deméneghi.

Esta es la descripción poética que la creadora del traje realizó de su atuendo: robando el blanco de la gardenia, que es la flor representativa del municipio, lo plasmo en él; en el brillo de sus listones se reflejan las nieves eternas del volcán Pico de Orizaba o Citlaltépetl, su encaje representa la espuma del río Metlac; su rebozo de color verde representa la exuberante vegetación que rodea a esta localidad; sus aretes y crucifijo de oro son un tributo a la herencia de nuestros antepasados. Los olanes de la falda y el taconeo de sus blancas zapatillas traen el rumor de los sones que baila la jarocha y coronando la altiva cabeza de la mujer fortinense un gran tocado de flores formado principalmente por gardenias y otras flores multicolores que reflejan el perfume y colorido de esta ciudad (figura 8). 


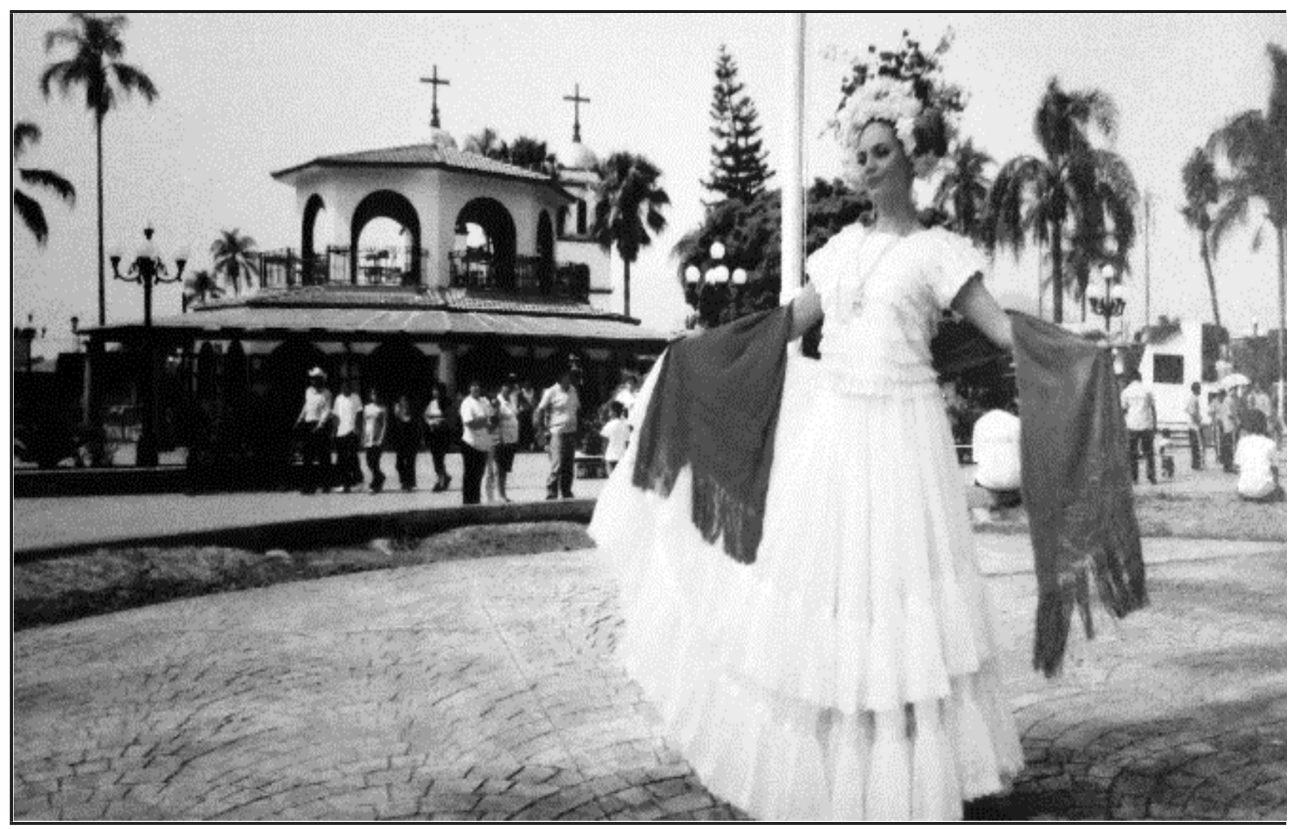

FIGURA 8

Modelo portando el traje típico: lleva en su cabeza el tocado de flores elaborado principalmente de gardenias

Fuente: imagen proporcionada por el Departamento de Turismo del Ayuntamiento de Fortín (2017).

Las expresiones artísticas en donde la gardenia figura como parte del reparto de un elenco de actores sobresalientes en la historia del municipio de Fortín se pueden apreciar en un mural que se encuentra en las escaleras de la parte interior del Palacio Municipal. Recientemente, en 2016, el maestro Quintín Pérez, famoso y reconocido pintor y muralista, oriundo de la localidad Coapichapa, ubicada en el municipio de Fortín, Veracruz, fue invitado a plasmar con su arte en las escaleras de este edificio los personajes, aspectos, situaciones y acontecimientos más representativos que a lo largo de la historia de este municipio han dejado una huella muy importante a través del tiempo. Su mural "Expresiones con lenguaje florido" es, en palabras de su autor, un canto hecho desde el sentimiento más puro de su corazón por esa tierra que lo vio nacer. Es un poema que se difunde entre la gente y la exuberancia del paisaje. Es un mosaico de figuras que desde su concepción artística tratan de impactar visualmente para atrapar al espectador y llevarlo en su recorrido a través de cafetales, cañales, fincas, bosques de otates y mafafas que desembocan en la majestuosidad de la barranca del Metlac. Es una composición plástica que incluye una muestra de la arquitectura, los personajes y las actividades que se desarrollan en este municipio.

Para el maestro Quintín, el hecho de incluir en su mural motivos referentes a la gardenia fue porque esta hermosa y perfumada flor le otorgó a este municipio el reconocimiento y denominación como Fortín de las Flores, y esto le otorga un valor social aún más importante que el de valor comercial. La gardenia fue una gran e importante fuente de empleo y de ingresos en la zona y originó que los agricultores vieran en el cultivo de flores y ornamentales una gran oportunidad de desarrollo aprovechando las bondades agroclimáticas que esta región ofrece para el cultivo de gran variedad de plantas. En su mural evoca el grato recuerdo del aroma que se esparcía en la estación del tren, en donde cientos de vendedores ofrecían sus flores a los viajeros y en donde se embarcaban millares de flores hacia la Ciudad de México o al sureste para su venta en los grandes mercados y no podía faltar en el mural la alberca del Hotel Ruíz Galindo, la cual se llenaba diariamente por miles de flores de gardenia que perfumaban sus frescas aguas dándole una fama y reconocimiento nacional e internacional, y que se conociera como "la alberca de las gardenias" (figura 9). 


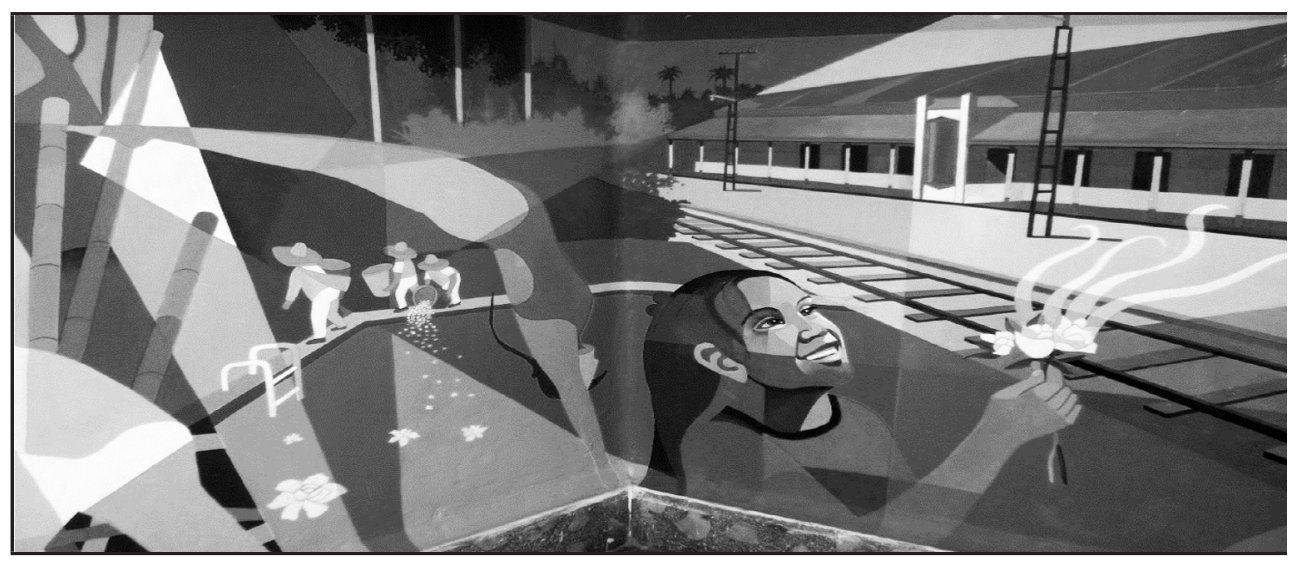

FIGURA 9

Fragmento del mural "Expresiones con lenguaje florido" del muralista Quintín Pérez. Está ubicado en el interior del Palacio Municipal de Fortín de las Flores, Veracruz

Fuente: fotografía tomada por Marco Rodríguez-Deméneghi.

Presente en la cultura y en expresiones artísticas, la gardenia también ha sido adoptada por comunidades aledañas al municipio de Fortín, que por su cercanía se podría pensar que son parte de él, y en donde posee un importante significado en sus ritos religiosos. Se ubicaron dos localidades en donde en las festividades de culto de los creyentes católicos referentes a los ritos de la Semana Santa la gardenia es utilizada por los hombres denominados "barones", que es una de las manifestaciones culturales desde el siglo pasado y que hasta nuestros días se han venido conservando y en donde el uso de la flor de gardenia adquiere un singular significado. Estas comunidades son Zapoapan, ubicada dentro del municipio de Ixtaczoquitlán, Veracruz, y Naranjal, de la cabecera municipal del mismo nombre en la zona centro del estado de Veracruz. Dichos municipios son colindantes al de Fortín.

El término de "barón" podría ser acuñado por la semejanza con José de Arimatea, quien en los evangelios de la biblia católica (Mateo, capítulo 27, versículos 57-60; Marcos, capítulo 15, versículos 43-46; Lucas, capítulo 23, versículos 50-55; Juan, capítulo 19, versículos 38-42), era un hombre rico perteneciente a la nobleza que vivió en la época de Jesús de Nazareth y a quien le fue entregado el cuerpo después de su muerte. Este acontecimiento le da un significado muy especial de título nobiliario a la denominación de los barones que participan en estas festividades en las comunidades señaladas. Se considera que la principal función del barón es custodiar el cuerpo de Jesucristo a partir de su muerte.

La existencia de los barones en Naranjal, Veracruz, es incierta según comenta el licenciado y cronista de la comunidad José Antonio Tepepa Acatecatl (comunicación personal, 2016). debido a los escasos datos que apoyen la fecha de su fundación. Narra que, de acuerdo con el testimonio del señor Ezequiel Soto, quien es una de las personas con más de 50 años de participación, hacia finales de la década de 1920 ya existía este grupo y estaba conformado por cuatro personas únicamente; su función era descender el cuerpo de Jesucristo de la cruz como lo hicieron, según relatos de los evangelios de la Sagrada Biblia, el barón José de Arimatea y Nicodemo. La vestimenta que en la actualidad utilizan los barones no ha variado desde los orígenes de esta tradición. Siempre ha sido una túnica y capa blanca, además de la corona de flores de gardenia. Según se sabe en aquella época la gente vestía habitualmente de túnica y un turbante con el fin de mantener fresca la cabeza. De acuerdo con el señor Soto, "la vestidura blanca era porque todos antiguamente en lugar de usar pantalones y camisa usaban túnica y capa. Era la usanza, el modo de vestir de las personas. Los romanos vestían de otro modo" (comunicación personal). En referencia con el uso de una corona de flores, comenta: "como las personas de aquel tiempo unas hasta usaban un tocado en la cabeza y con eso se viene a representar con la corona”. Pero la corona de gardenias tiene un significado aún más importante como lo señala el licenciado, Tepepa: 
Los Barones utilizan las flores de gardenia por su singular aroma y que al igual que como se narra en los evangelios José de Arimatea, ungió con perfumes el cuerpo de Jesucristo al momento de su sepultura, el aroma de las flores de la gardenia viene a representar esto aunado a que por su extraordinario color blanco representa la pureza, paz y castidad. Se puede deducir que el aroma de las gardenias sugiere los bálsamos con los que fue ungido Jesús aquel día de su sepultura.

En la comunidad Naranjal, a diferencia de Zapoapan, del municipio de Ixtaczoquitlán, Veracruz, en donde también existe la participación de los barones, no existe un número límite para poder participar como tal. En 2016 participaron 25 hombres, pero han llegado a contar con la participación de hasta 45 y en Zapoapan deben ser 8 como máximo, incluso aceptar uno más. Los requisitos que se deben cumplir para ser barón es estar casado por la iglesia o soltero sin vivir en unión libre, la edad oscila entre los 15 y 80 años.

Por su parte el Señor Enrique García (comunicación personal, 2016), quien funge como coordinador de los apóstoles y barones en Zapoapan, nos comenta que no existe un registro en los archivos de la parroquia en donde se señale el inicio de esta tradición, pero se toma como referencia 1951 que fue donde llegó a la comunidad el Cristo que ellos veneran. Al igual que en Naranjal, el requisito para participar es estar casado por la iglesia o soltero, a estas personas los mueve la fe, la buena voluntad y, para conservar esta bella tradición que viene desde sus abuelos, todos los participantes son oriundos de esta localidad y la edad mínima para participar es de 15 años en adelante. Es importante señalar que existe un fuerte arraigo de esta tradición; para los hombres jóvenes es un gran orgullo participar como barón.

La corona de flores está conformada única y exclusivamente de flores de gardenia, las cuales están ubicadas en una base de aro de doble bastidor de madera en donde mínimo deben estar incrustadas 300 flores, esto en el caso de Naranjal; en Zapoapan la base de aro es de un solo bastidor con promedio de entre 100 a 150 flores y en ambos casos los mismos barones deben elaborarlas (figura 10). Muchas de estas flores son adquiridas de huertas productoras del municipio de Fortín; Zapoapan cuenta también con zonas productoras.

En voz de los propios barones, la flor de la gardenia representa la pureza, la humildad, la alegría y su aroma asemeja el perfume con el que el cuerpo de Jesucristo fue ungido al momento de su muerte; no hay otra flor que se pueda comparar con este exquisito aroma.

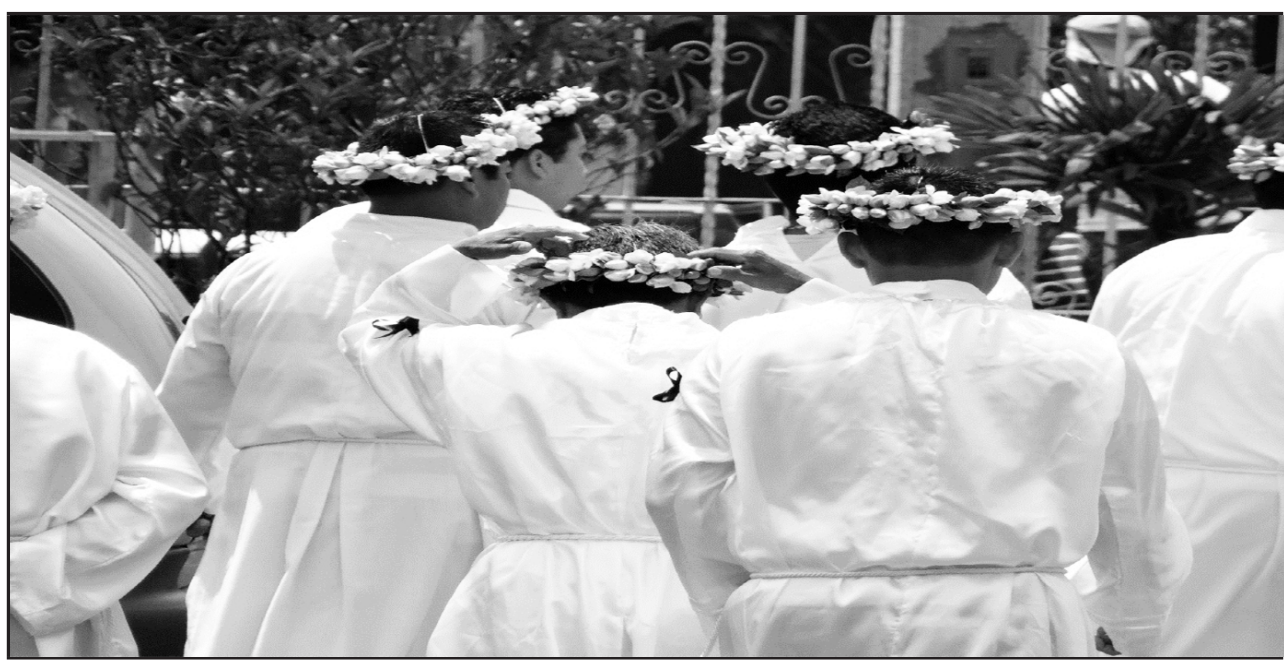

FIGURA 10

Barones" de la comunidad de Zapoapan en las festividades de la Semana Mayor en 2016 portando la tradicional corona de gardenias

Fuente: fotografía tomada por Marco Rodríguez-Deméneghi. 


\section{AnÁlisis Prospectivo: El FUTURo de la gardenia EN LA AGROINDUSTRIA}

La fragancia de la gardenia es muy empleada como flor de corte y maceta y en menor medida en la elaboración de perfumes, pero también es portadora de sustancias con diversas propiedades medicinales de gran valor agregado si se industrializan en la región. Las sensaciones relajantes y refrescantes del olor a gardenia sugieren sus aplicaciones en cuidado del cuerpo, productos de limpieza y perfumes. Este estudio prospectivo está centrado en abordar el creciente interés en fragancias florales, productos naturales, inocuos y de la región. El perfil de aroma y la propiedad sensorial de esta dulce y elegante fragancia fortalecerá y ampliará en aplicaciones de hojas y pétalos de gardenia desde la medicina tradicional a las de perfumería y al campo de la fitoquímica (Kanlayavattanakul y Lourith, 2015).

En este sentido, los extractos de pétalos y hojas de gardenia y sus principales fitoconstituyentes activos han sido descritos por diversos autores con una amplia gama de actividades farmacológicas, como antihiperglicémicos, antiateroscleróticos, antiinflamatorios, antiartritis, anticancerígenos, antiapoptóticos, antidepresivos y ansioliticos, antioxidantes, antiangiogénicos, antitrombótico, actividades antimicrobianas y misceláneas. También, se ha explorado su efecto protector a través de diversos mecanismos como neuroprotectores para la enfermedad de Alzheimer, hepatoprotector, gastroprotector, retinoprotector, actividades protectoras de la piel, nefroprotectoras, los cuales son reportados por Parmar y Sharma (2000), Wang et al. (2004), Koo et al. (2004; 2006), Song et al. (2013), Phatak (2015), Zhang et al. (2017), Xiao et al. (2017) y Wang et al. (2018). Esto permite visualizar un desarrollo sostenible para esta agroindustria basada en la flor de gardenia en la región centro de Veracruz.

Por otra parte, el trabajo de Miao et al. (2016) concluyó que para establecer una agroindustria integral y sostenible del uso de la gardenia es necesaria la aplicación de modelos espaciales y agroclimáticos como ArcGIS y Maxent para analizar la idoneidad ecológica de Gardenia jasminoides y la selección de factores ecológicos. Los resultados mostraron que la precipitación promedio en abril, agosto y noviembre son los factores más importantes que afectan el crecimiento de la gardenia.

En su caso, los trabajo de Zhou et al. (2015) y Palmateer y Chase (2016) establecieron que con el fin de proporcionar una base sostenible para obtener un alto contenido de componentes efectivos de Gardenia jasminoides se deben seleccionar los fertilizantes y pesticidas adecuados para el cultivo, en especial de origen orgánico para maximizar los compuestos eficaces y minimizar metales pesados y residuos de plaguicidas.

\section{Conclusiones}

La gardenia es una hermosa flor blanca con exquisito aroma que fue adoptada por el municipio de Fortín desde 1882, cuando fue introducida por Antonio Polanco y logró posicionarse como la flor representativa de esta localidad y a la cual se le debe el reconocimiento como el Fortín de las Flores, nombre que adquiere en su cabecera municipal. Llegó a ser de tanta importancia que entre 1940 y 1960 logró su mayor auge comercial, social, religioso y cultural. Referirse a la gardenia es regresar al pasado y recordar a un exuberante y colorido paraíso tropical ubicado en la parte central del estado de Veracruz, México, que al igual que las eternas nieves del volcán Citlaltépetl es parte irremplazable de su paisaje. Esta flor se esparcía como un manto blanco de flores con un agradable y perfumado aroma llevado por el viento convirtiendo el lugar en un mágico encuentro con la naturaleza, la armonía, el regocijo, la quietud y la paz. Se podría considerar a la gardenia una planta representativa y útil para el municipio de Fortín, tal y como se describe en la etnobotánica (Rivera et al., 2006), que etimológicamente se refiere a las plantas útiles y su relación con el hombre, en donde es reconocida como un recurso natural presente en temas sociales, políticos, biológicos y económicos a través de su historia. Recientemente, la Universidad Veracruzana, a través de la Facultad de Ciencias Biológicas y Agropecuarias, con la colaboración de la Facultad de Ciencias Químicas, ha encontrado en la gardenia un amplio potencial para la industria cosmética y alimenticia. 
Hoy en día, diversas condicionantes, como el cambio de uso del suelo, de pasar de zonas agrícolas a zonas habitacionales, la cancelación del tren de pasajeros que hacía escala en Fortín, la creación de la autopista México-Veracruz que provocó que el viajante ya no se detuviera en esta ciudad, los problemas del campo en nuestro país y el poco apoyo a este sector, han sido factores para que la zona productora haya disminuido considerablemente, pero, aun con todo esto, en municipios aledaños a Fortín han adoptado el cultivo de la gardenia y es una fuente importante de ingresos para familias campesinas. El perfume de gardenias se ha ido alejando de Fortín para irse a esparcir a nuevas montañas, a nuevos campos, a nuevas zonas, a nuevas localidades y a llenar con su hermoso manto blanco el colorido de los campos agrícolas de la zona central del estado de Veracruz, pero siempre reconociendo que la cuna de la gardenia en nuestro país se origina aquí. Diversas expresiones artísticas le hacen referencia (Arnold, 2006), y tal cual reza la famosa canción "Perfume de gardenia" del puertorriqueño Rafael Hernández Marín conocido como el Jibarito (1892-1965) y que hiciera famosa la agrupación musical Sonora Santanera, "Perfume de gardenias tiene tu boca, perfume de gardenias, perfume del amor...", así también perfume de gardenias tiene tu historia Fortín de las Flores.

\section{Agradecimientos}

Se agradecen los comentarios de los árbitros de la revista que mejoraron sustancialmente el contenido del artículo.

\section{ReFERENCIAS}

Arnold, E. (2006). Gênero e história nas obras Perfume de gardenia e Solitária solidária da escritora venezuelana Laura Antillano. Universidade Federal do Rio Grande do Sul. Instituto de Letras. Programa de Pós-Graduação em Letras, Porto Alegre. Disponible en http://www.lume.ufrgs.br/bitstream/handle/10183/10920/000602974.pdf ?sequence $=1$

Ayuntamiento de Fortín (2019). Historia. Disponible en http://www.fortin.gob.mx/.

Baines, J. y Key, C. (1974). El ABC de las plantas de interior. Madrid: Editorial Blume.

Barbano, M. M. M., Gómez, L. H. y Lozada, D. I. M. (2016). Ser coleto: plantas en las casas de El Cerrillo, San Cristóbal de las Casas, México. Culturales, 3(2), 181-208. Disponible en http://www.scielo.org.mx/scielo. php?pid=S1870-11912015000200006\&script=sci_arttext\&tlng=pt

Blanco, M. C. M. C. y Castro, A. B. S. (2007). El muestreo en la investigación cualitativa. Nure Investigación, 27, 1-4 Disponible en http://www.sc.ehu.es/plwlumuj/ebalECTS/praktikak/muestreo.pdf

Blanco, A. J. (2003). Pequeño bosquejo monográfico de El Fortín. Archivo de la Biblioteca Municipal de Fortín de la Flores Veracruz.

Cabral, I. (1966). Fortín de las Flores. Revista Jarocha, 45(7), 1-30.

Consejo Ciudadano A. C. (2009). Documentos para la historia de Fortín de las Flores. Orizaba: Editorial Impresos Gráficos Guerrero.

Davis, P. H. (1979). The identification of flowering plant families including a key to thoses native and Cultivated in north temperat regions. London: Cambrige University Press.

Del Cañizo, J. A. (1977). Plantas en el hogar. Madrid: Mundi-Prensa.

De Latina, M. V., Ávila, O. E. y Delgado, L. C. (2001). Producción comercial de Gardenia jasminoides Ellis en Tucumán, Argentina. Disponible en http://www.faz.unt.edu.ar/images/stories/pdfs/ pva/0161.pdf

Denny, M. (1948). Naming the Gardenia. Scientific Monthly, 67, 17-21

Domínguez, R. J. (1971). El encanto apacible de mi tierra Coscomatepec. México: Trillas. 
Durán, V. T. C. (2006). Diagnóstico del cultivo de la gardenia (Gardenia jasminoides) en la región central del Estado de Veracruz. Córdoba: Universidad Veracruzana.

Escalante, E. R. (2008). La Floricultura. Boletín 17/08. Comercialización ASERCA Región Peninsular. Disponible en http://upax.mx/wp-content/uploads/2013/09/floricultura-ACERCA.pdf

Fernández, N. R. (1986). Flora de Veracruz. Instituto Nacional de Investigaciones sobre Recursos Bióticos. Fascículo 56. Disponible en http://www1.inecol.edu.mx/publicaciones/resumeness/FLOVER/54-hernandez.pdf

García-Alonso, O., Goméz-Gómez, A. A., Chalita-Tovar, L. E., Brambila-Paz, J. D. J. y García-Alonso, R. (2014). Factibilidad financiera por opciones reales para la producción de Anturio (Anthurium andreanum Lindem Ex Andre) en Cuitláhuac, Veracruz. Revista Mexicana de Ciencias Agricolas, 8, 1467-1475

Gómez-Gómez, A. A. y Carrillo-Ángeles, R. Y. (2014). Producción y comercialización de flores mexicanas. España: ECOFARN. Disponible en https://www.google.com.mx/search?rlz=1C1CHBF_esMX800MX800\&$\mathrm{q}=\mathrm{G} \% \mathrm{C} 3 \% \mathrm{~B} 3 \mathrm{mez}-\mathrm{G} \% \mathrm{C} 3 \% \mathrm{~B} 3 \mathrm{mez},+\mathrm{A} .+\mathrm{A} .,+\mathrm{y}+$ Carrillo-\%C3\%81 ngeles, + R.+E.+Y.+(2014).+Produc$\mathrm{ci} \% \mathrm{C} 3 \% \mathrm{~B} 3 \mathrm{n}+\mathrm{y}+$ comercializaci\%C3\%B3n+de+flores+mexicanas. + ECOFARN\&spell=1\&sa=X\&ved=0ahUKEwiJ4bDjybjdAhUQ7qwKHdkSBngQBQgkKAA\&biw=1366\&bih=613

González, J. M., Espinosa, H. L. y Torres, I. L. (2007). La horticultura ornamental en el estado de Veracruz, México. Actas de Horticultura Sociedad Española de Ciencias Hortícolas, 48, 485-488. Disponible en https:// www.researchgate.net/profile/Joaquin_Murguia-Gonzalez/publication/268413607_La_horticultura_ornamental_en_el_estado_de_Veracruz_Mexico/links/54f374560cf24eb8794c2d06.pdf

Hernández Meneses, F., Licona Vargas, A. L., Pérez Portilla, E., Cisneros Solano, V. M. y Díaz Cárdenas, S. (2012). Diversificación productiva café-plantas ornamentales en La Sidra, Atzacan, Veracruz. Revista de Geografía Agrícola, 48-49.39-50 Disponible en https://chapingo.mx/revistas/revistas/articulos/doc/rga-1678.pdf

INAFED. (2010). Fortín. Instituto para el Federalismo y el Desarrollo Municipal. SEGOB [monografías de los municipios de México]. Disponible en http://siglo.inafed.gob.mx/enciclopedia/EMM30veracruz/ municipios/30068a.html

Jarvis, C. E., DuVal, A., \& Crane, P. R. (2014). Gardenia jasminoides: A traditional Chinese dye plant becomes a garden ornamental in Europe. Curtis's botanical magazine, 31(1), 80-98.

Kanlayavattanakul, M., \& Lourith, N. (2015). Volatile profile and sensory property of Gardenia jasminoides aroma extracts. Journal of Cosmetic Science, 66(6), 371-377.

Koo, H. J., Song, Y. S., Kim, H. J., Lee, Y. H., Hong, S. M., Kim, S. J., ... y Park, E. H. (2004). Antiinflammatory effects of genipin, an active principle of gardenia. European Journal of Pharmacology, 495(2-3), 201-208.

Koo, H. J., Lim, K. H., Jung, H. J., \& Park, E. H. (2006). Anti-inflammatory evaluation of gardenia extract, geniposide and genipin. Journal of Ethnopharmacology, 103(3), 496-500.

Jarvis, C. E., DuVal, A., \& Crane, P. R. (2014). Gardenia jasminoides: A traditional Chinese dye plant becomes a garden ornamental in Europe. Curtis's botanical magazine, 31(1), 80-98.

Landero Torres, I., García Martínez, M. A., Oliva Rivera, H., Galindo Tovar, M. E., Lee espinosa, H., \& Murguía González, J. (2010). Comparison of two soil ant samplings from Metlac gully, Fortin de las Flores, Veracruz, Mexico. Revista Cientifica UDO Agrícola, 10(1), 173-178.

Landero-Torres, I., García-Martínez, M. Á., Galindo-Tovar, M. E., Leiva-Ovalle, O. R., Lee-Espinosa, H. E., Murguía-González, J. y Negrín-Ruiz, J. (2014). Un cultivo ornamental de heliconias como Reservorio de la mirmecofauna nativa: un caso de horticultura tropical en el centro de Veracruz, México. Southwestern Entomologist, 39(1). 135-146

Martínez H. A. (2015). Diagnóstico del subsector agrícola del estado de Veracruz. Disponible en http://repositorio.uaaan.mx:8080/xmlui/bitstream/handle/123456789/5190/T16717 MARTINEZ HERNANDEZ, ALEJANDRO TESIS.pdf ? sequence $=1$

México Desconocido. (2014). Special Guidebook. Revista México Desconocido-Discover Veracruz. Impresiones Aéreas, S. A. de C.V., México. Pág. 88 
Montalvo, J. M., Juárez, J. R., Espinoza, J. A. M. y Ramírez, N. P. (2017). El sistema de producción del brócoli desde la perspectiva del campo social de Pierre Bourdieu. Estudios Sociales. Revista de Alimentación Contemporánea y Desarrollo Regional, 27(50), 1-13

Miao, Q., Yuan, Y. J., Luo, G. M., Wei, C. H., Rao, Y. Q., Gong, Y. H.,... \& Dong, Y. K. (2016). Study on ecological suitability of Gardenia jasminoides based on ArcGIS and Maxent model. China Journal of Chinese Materia Medica, 41(17), 3181-3185.

Morales, F. (2010). Imágenes de la industria turística en México 1950-1975. Archipiélago. Revista cultural de nuestra América, 13(47). 60-64.

Murguía-González, J., Leyva-Ovalle, O. R., Lee-Espinosa, H. E., Galindo-Tovar, M. E., Pardío-Sedas, V. T. y Llarena-Hernández, R. C. (2016). Sistemas de producción de orquídeas (Orquidaceae) en Veracruz, México. Agroproductividad, 9(6), 62-66.

Murguía-González, J., Riestra-Díaz, D., Gallardo-López, F., Alonso-López, A., Olguín-Palacios, C., Cruz-Castillo, J. G., \& Flores-Murguía, A. (2003). Caracterización de factores socioeconómicos del cultivo de anturio (Anthurium andreanum linden) en el estado de Veracruz, México. Revista Chapingo. Serie Horticultura, 9(1), 163-177.

Novo-Valencia G. (2016). Semblanza del Hotel Ruiz Galindo. Disponible en http://www.diariodelistmo.com/ resumen/vida-y-sociedad/21561/semblanza-del-hotel-ru-z-galindo.html

Osuna, O. E. P., Betancur, F. R. y Espinosa, H. R. (2016). Dinámica del cultivo y mercado de flores en México, 1995-2012. UGCiencia, 22(1), 111-118.

Palmateer, A. J., \& Chase, A. R. (2016). Diseases of Gardenia. Handbook of Florists' Crops Diseases, 1-13.

Parmar, V. S., \& Sharma, S. K. (2000). Novel Constituents of Gardenia Species-A Review. Journal of Scientific \& Industrial Research, 59, 893-903

Pasquel, L. (1966). Fortín de las Flores. Revista Jarocha, 45(7), 3-14.

Phatak, R. S. (2015). Phytochemistry, pharmacological activities and intellectual property landscape of Gardenia jasminoides Ellis: a review. Pharmacognosy Journal, 7(5).254-265

Rimache, A. M. (2009). Floricultura, cultivo y comercialización. Lima: Grupo Editorial Macro, S. P. C.

PicClik (2019). Hotel Ruiz Galindo Pool, 1948. Disponible en https://picclick.com/RPPC-FORTIN-VERACRUZ-Mexico-291662444636.htm

Rivera, N. D. y Obón, D. C. C. (2006). Etnobotánica Capitulo 1. Manual de Teoria y Prácticas. España. Disponible en http://ocw.um.es/ciencias/etnobotanica/Material\%20de\%20clase/etnobotanica-capitulo1-2007

Rodríguez- Deméneghi, M. V., Gallardo, L. F., Lee, E. H. E., Galindo, T. M. E., Aguilar, R. N., Leyva, O. O. R., Burchi, G., Landero, T. I., Murguía, G. J. (2016). El cultivo de Gardenia Jasminoides Ellis en la región central de Veracruz. Agroproductividad, 9(6), 39-45.

Romero, H. M. (1986). Crónica de un mexicano de tiempo completo. México: Editorial Unicornio.

SEP. (1991). Veracruz. Pródiga naturaleza de cara al mar. Secretaría de Educación Pública. Monografía Estatal. México.

SIAP (Servicio de Información Agroalimentaria y Pesquera). (2017a). Disponible en http://infosiap.siap.gob. $\mathrm{mx}: 8080$ /agricola_siap_gobmx/AvanceNacionalSinPrograma.do

SIAP (Servicio de Información Agroalimentaria y Pesquera). (2017b). Disponible en https://www.gob.mx/ snics/acciones-y-programas/publicaciones-ornamentales

Song, J. L., Yang, Y. J., Qi, H. Y., \& Li, Q. (2013). Chemical constituents from flowers of Gardenia jasminoides. Journal of Chinese Medicinal Materials, 36(5), 752-755.

Tiscornia, J. R. (1963). Cultivo de flores y plantas de adorno. Buenos Aires: Hachette.

Vega, T. J. (2005). Hotel Boutique en Fortín Veracruz. Disponible en http://catarina.udlap.mx/u_dl_a/tales/ documentos/lar/jimenez_v_t/resumen.html 
Villalobos, P. R. (1997). Antecedentes históricos de Fortín de las Flores. Monografía Gráfica. Ayuntamiento de Fortín 1995-1997.

Vizcaíno, R. (1981). Organización del turismo y carencias de infraestructura. Disponible en http://cdigital. uv.mx/bitstream/123456789/34944/2/198116E5.pdf

Voces Libres. (2005). Revista mensual independiente, 2(18).

Wang, S. C., Tseng, T. Y., Huang, C. M., \& Tsai, T. H. (2004). Gardenia herbal active constituents: Applicable separation procedures. Journal of Chromatography B, 812(1-2), 193-202.

Wang, X., Wang, G. C., Wang, S. W., Ng, T. B., Zhang, K. Y., Lee, K. F.,... \& Sze, S. C. W. S. (2018). Identification of steroidogenic components derived from Gardenia jasminoides Ellis potentially useful for treating postmenopausal syndrome based on network and systemic pharmacological approaches. Frontiers in Pharmacology, 9, 390.

Xiao, W., Li, S., Wang, S., \& Ho, C. T. (2017). Chemistry and bioactivity of Gardenia jasminoides. Journal of Food and Drug Analysis, 25(1), 43-61.

Xiao, R. C., Luo, G. M., Dong, L. H., Zhu, Y. Y., Zhu, J. X., Zhang, F. B., \& Wu, S. N. (2017). Comparison of chemical constituents in different parts of Gardenia jasminoides based on multiple wavelength HPLCDAD. China Journal of Chinese Materia Medica, 42(23), 4636-4640.

Zhang, H., Feng, N., Xu, Y. T., Li, T. X., Gao, X. M., Zhu, Y.,... \& Wu, H. H. (2017). Chemical constituents from the flowers of wild Gardenia jasminoides J. Ellis. Chemistry \& Biodiversity, 14(5).

Zhou, M., Tang, L., \& He, G. (2015). Effects of different fertilizers and pesticides on effective components, heavy metal and pesticide residue in fruits of Gardenia jasminoides Ellis. Journal of Southern Agriculture, 46(11), 1965-1969.

\section{Notas}

[1] Disponible en http://www.theplantlist.org/tpl/record/kew-88270.

\section{BY-NC-ND}

